\title{
Particulate matter emissions from gasoline direct injection spark ignition engines
}

\author{
F Leach, R Stone \\ Department of Engineering Science, University of Oxford, UK \\ D Fennell, D Hayden, D Richardson, N Wicks \\ Powertrain Research, Jaguar Cars Ltd, UK
}

\begin{abstract}
An index, linking fuel composition with Particulate Matter (PM) emissions (PN index) has been developed and here is evaluated with model fuels in a single cylinder, optical access, Spray Guided Direct Injection (SGDI) engine. Imaging of in-cylinder evaporation shows the composition of model fuels affects their PM emissions.

Emissions are evaluated from two fuels representing the EU5 reference-fuel specification, developed using the PN index to give a difference in PM emissions, showing a $40 \%$ variation.
\end{abstract}

The index is investigated in a Jaguar V6 engine with five different fuels over a simulated NEDC. The results show the index trends are followed.

1

INTRODUCTION

Gasoline Direct Injection (GDI) engines have become the preferred standard for gasoline light-duty vehicles in the worldwide market, replacing Port Fuel Injection (PFI) engines due to their better specific fuel consumption and lower $\mathrm{CO}_{2}$ emissions. GDI engines emit more Particulate Matter (PM) than PFI engines [1]. Without optimisation for reduced particulate emissions, modern GDI engines might not meet increasingly stringent EU emissions legislation [2]. Forthcoming European emissions legislation, EU6 - effective 1 September 2014, mandates a particle limit of $6 \times 10^{11} \mathrm{\#} / \mathrm{km}$ (with derogation to $6 \times 10^{12} \# / \mathrm{km}$ permitted for 3 years) [3].

Aikawa et al. [4] conducted tests with a PFI engine and developed a model linking fuel composition with PM emissions. It links PM emissions with the Vapour Pressure $(V P)$ and Double Bond Equivalent (DBE) of the components in the fuel weighted by Mass Fraction $\left(W_{t}\right)$ :

$$
P M \text { index }=\sum_{i=1}^{n}\left[\frac{D B E_{i}+1}{V P_{i}}\right] W_{t i}
$$

DBE is a measure of how unsaturated a hydrocarbon is, and can be easily calculated from:

$$
D B E=\frac{2 C-H+2}{2}
$$

Where $C$ and $H$ are the number of Carbon and Hydrogen atoms respectively present in an organic compound. As an example, toluene (methyl benzene, $\mathrm{C}_{6} \mathrm{H}_{5} . \mathrm{CH}_{3}$ ) has a 
$D B E$ of 4 as the corresponding saturated compound would be heptane $\left(\mathrm{C}_{7} \mathrm{H}_{16}\right)$, which has a DBE of 0 . The Vapour Pressure $(V P)$ is evaluated at $443 \mathrm{~K}$ by means of an empirical correlation.

In an initial investigation (Leach et al. (2013) [5]), a PN index was introduced, with the Vapour Pressure being evaluated as Dry Vapour Pressure Equivalent (DVPE) with units of $\mathrm{kPa}$ and the use of volume fraction $\left(V_{\mathrm{i}}\right)$ [5]. The DVPE was used since this is a European standard measurement evaluated at $310.95 \mathrm{~K}$.

$$
P N \text { index }=\frac{\sum_{i=1}^{n}\left[D B E_{i}+1 / V_{i}\right.}{D V P E(\mathrm{kPa})}
$$

Leach et al. (2013) [5] investigated the PN and PM indices on a single cylinder engine. This was validated against a spectrum of model fuels, and two commercially available gasolines. These results showed that the trends of the PN index were followed, and prompted the more detailed study in this paper. One of the effects reported was the importance of the presence of a light fraction ( $n$ pentane) in the model fuels, to accurately mimic commercial gasoline, in particular the spray break-up in-cylinder. This was shown by use of a fast flame ionisation detector (fFID) to show in-cylinder hydrocarbon levels on the single cylinder engine. The fuel with $5 \% \mathrm{v} / \mathrm{v} \mathrm{n}$-pentane showed much greater variation around the annulus, and cycle-to-cycle than the fuel without, giving a more dispersed but less repeatable mixture formation, shown in Figure 1 . This effect is further investigated here with a fFID and high-speed spray imaging.

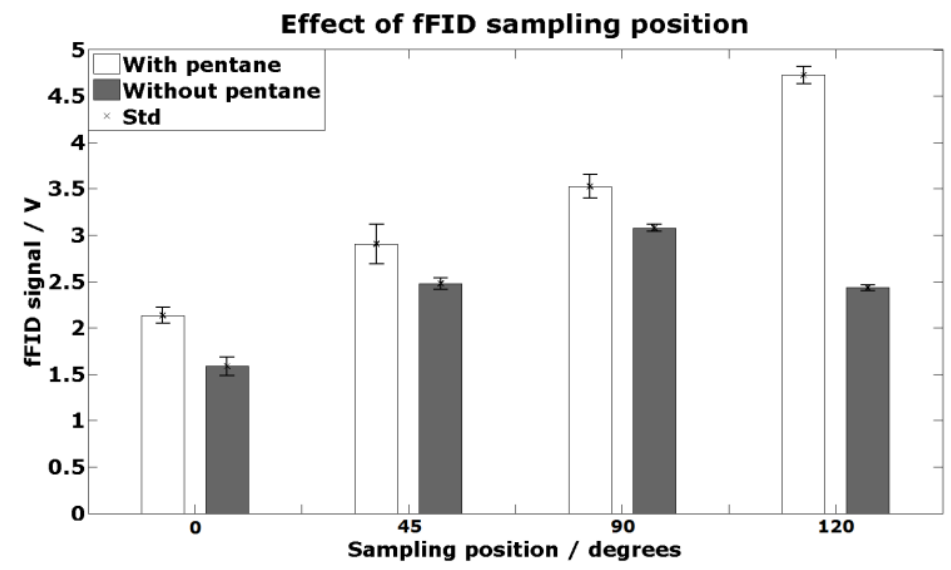

Figure 1: Effect of annular sampling position on the peak fFID signal for fuels with and without pentane; the standard deviation bars indicate the cycle-to-cycle variations in the mixture $\left(0^{\circ}\right.$ is the front of the engine)

As the trends of PN index had been shown to hold for commercially available gasolines, the Euro 5 emissions standards were investigated. The standard specifies a parameter range for the test fuel [6]. The parameters of the specification relevant to the PN index can be seen in Table 1.

Table 1: Reference fuel specification [6]

\begin{tabular}{lrc}
\hline & \multicolumn{1}{c}{ Min } & Max \\
\hline DVPE $(\mathrm{kPa})$ & 56.0 & 60.0 \\
Olefins $(\% \mathrm{v} / \mathrm{v})$ & 3.0 & 13.0 \\
Aromatics $(\% \mathrm{v} / \mathrm{v})$ & 29.0 & 35.0 \\
\hline
\end{tabular}


These parameters can be arranged to give a maximum and minimum PN index possible with a reference fuel meeting the specification, as seen in Table 2 . It can be seen that a variation in the index of approximately $24 \%$ is theoretically possible.

Table 2: Reference fuel parameters for greatest PN index variation

\begin{tabular}{lrr}
\hline & Min PNI & Max PNI \\
\hline DVPE $(\mathrm{kPa})$ & 60.0 & 56.0 \\
DBE $+1(\% \mathrm{v} / \mathrm{v})$ & 2.19 & 2.53 \\
PN index $(1 / \mathrm{kPa})$ & 3.65 & 4.51 \\
\hline
\end{tabular}

The PN index is of course not an exact quantity, and a potential error can be calculated on it, by filtering down the reproducibility from the appropriate test methods (specified in [6]), and assuming a 'worst case' effect of each of the errors. These error bars have been plotted on the displayed PN index on the experimental results.

Here the PN index is tested on two engines with several fuels. Model fuels, with independent control of DBE and VP, and two reference fuels have been tested on a single cylinder, optical access engine at light load. Five different fuels have been tested on a V6 engine, simulating a NEDC, and the results compared to the PN index.

2

EXPERIMENTAL METHODOLOGY

The work described in this paper is split into two phases. The first, conducted on the single cylinder engine, has been conducted at steady state, light load (1500 rpm, 2 bar BMEP); the second, on the V6 over a simulated New European Drive Cycle (NEDC). It should be stressed that the latter test is not a legally compliant test, as it is not being performed with a vehicle on a chassis dynamometer, or with the correct particle sampling procedure.

\subsection{Engines}

The engine for the model and reference fuel work is a single cylinder optical access Spray Guided Direct Injection (SGDI) engine supplied by Jaguar. The combustion system is essentially the same as that used in the Jaguar AJ133 engine, which has been comprehensively described by Sandford et al. [7]. Table 3 shows the engine specification. This engine is not fitted with a catalyst. A lambda sensor was used to measure oxygen content in the exhaust and to set the correct fuel injection pulse width to achieve the mixture stoichiometry required for the test, either nominal stoichiometric $(\lambda=1.01)$ or $10 \%$ rich $(\lambda=0.9)$. As slight rich mixture excursions have a large effect on particulate emissions [8], a lambda of 1.01 was chosen to avoid these.

Table 3: Specifications of the single cylinder optical access SGDI engine

\begin{tabular}{lr}
\hline Bore $\times$ Stroke & $89 \times 90.3 \mathrm{~mm}$ \\
Displacement & $562 \mathrm{~cm}^{3}$ \\
Valves per cylinder & 2 intake, 2 exhaust \\
Compression ratio & $11.1: 1$ \\
Fuel pressure & $150 \mathrm{bar}$ \\
\hline
\end{tabular}

The drive cycle work was performed on an AJ126 3.0 L V6 supercharged engine. The AJ126 is based on the AJ133 V8 [7], the quad-cam V6 shares its all-aluminium 
construction with the $A J 133$. The supercharger is mounted in the ' $\mathrm{V}$ ' of the engine and is a Roots-type twin vortex supercharger. The engine is fitted with a watercooled intercooler, and Bosch engine management software. The engine was fitted with a standard three-way-catalyst. Table 4 shows the engine specification.

\section{Table 4: Specifications of the AJ126 V6 engine}

\begin{tabular}{lr}
\hline Bore $\times$ Stroke & $84.5 \times 89.0 \mathrm{~mm}$ \\
Displacement & $2995 \mathrm{~cm}^{3}$ \\
Valves per cylinder & 2 intake, 2 exhaust \\
Compression ratio & $10.5: 1$ \\
Maximum fuel pressure & $150 \mathrm{bar}$ \\
\hline
\end{tabular}

For these experiments the engine was mounted on a transient dynamometer set to run a simulated cold-start NEDC. The engine was loaded as a Sports Utility Vehicle (or similar) and stop-start technology was enabled.

\subsection{Instrumentation}

Two particulate measurement instruments have been used. A Cambustion DMS500 (DMS), and an AVL Particle Counter (APC). The DMS uses electrical mobility measurements of particles to give particle size, number and mass; it is fully described in [9]. The APC is a condensation particle counter, only giving particle number, it is fully described in [10], and it can be used as part of a legally compliant counting system. The sampling point for both particle measuring instruments was in the centre of the exhaust flow, several metres downstream of the exhaust valves, and (in the case of the V6) post-catalyst. For the steady state measurements on the single cylinder optical access engine, a sample of at least $90 \mathrm{~s}$ was taken, and averaged. The NEDC experiments were run at least three times and averaged.

In-cylinder Hydrocarbon (HC) levels were measured using a Cambustion HFR400 fFID [11], which measures hydrocarbon levels by chemi-ionization. For this experiment the hydrocarbon sample was taken at the circumference of the cylinder, approximately $10 \mathrm{~mm}$ below the cylinder head. The system response time was around $4 \mathrm{~ms}$, which corresponds to $36^{\circ}$ crank angle (CA) at $1500 \mathrm{rpm}$.

A Photron FASTCAM-1024PCI model 100K colour camera was used to record the injection and combustion images in the single cylinder optical access engine at a rate of 6000 frames per second (fps), which corresponds to 1 frame per $1.5^{\circ} \mathrm{CA}$ at $1500 \mathrm{rpm}$. At this frame rate a resolution of up to $512 \times 256$ or $384 \times 368$ pixels was available. The fuel spray was illuminated using a green LED array, pulsed synchronously with the spray and over-driven to provide sufficient illumination. Further information on the Data Acquisition (DAQ) system, and control of the single cylinder engine is described in [12]. The transient dynamometer used for the V6 tests was controlled by a 'turn-key' CP Engineering system.

\section{3}

\section{FUELS}

Model fuels were designed such that there was independent control of volatility and DBE, whilst still mimicking, as was best possible, commercial fuel performance. The nomenclature adopted here is the same as in [5] (' $\mathrm{T}$ ' fuels indicating a change in DBE, and ' $D$ ' fuels a change in volatility). The properties of the model fuels are shown in Table 5 and detailed compositional breakdown of the fuels can also be seen in [5]. 
Given the PM emissions trends followed the index for the model fuels, it was decided to have blended two fuels, which would meet the EU5 (CEC RF-02-08) reference fuel specification. The relevant parameters of their composition can be seen in Table 6. Unfortunately, the blending process was unable to meet the volatility specification exactly, but the error is small, and these two fuels are certainly representative of the CEC RF-02-08 specification.

Table 5: Model fuel composition

\begin{tabular}{|c|c|c|c|c|}
\hline Fuel & $\begin{array}{l}\text { DBE+1 } \\
(\% \mathrm{v} / \mathrm{v})\end{array}$ & $\begin{array}{c}\mathbf{V P}^{\mathbf{1}} \\
(\mathrm{kPa})\end{array}$ & $\begin{array}{c}\text { PM index } \\
(1 / \mathrm{kPa})\end{array}$ & $\begin{array}{c}\text { PN index } \\
(1 / \mathrm{kPa})\end{array}$ \\
\hline T0 & 1.00 & 15.79 & 0.341 & 6.33 \\
\hline T25 & 1.95 & 14.59 & 0.511 & 13.4 \\
\hline $\mathrm{T} 35^{2}$ & 2.33 & 14.40 & 0.615 & 16.2 \\
\hline T42 & 2.60 & 14.05 & 0.692 & 18.5 \\
\hline T50 & 2.90 & 13.66 & 0.762 & 21.2 \\
\hline T75 & 3.85 & 12.61 & 0.987 & 30.5 \\
\hline T100 & 4.80 & 11.73 & 1.19 & 40.9 \\
\hline $\mathrm{DO}^{2}$ & 2.33 & 14.40 & 0.615 & 16.2 \\
\hline D10 & 2.33 & 13.90 & 0.789 & 16.8 \\
\hline D20 & 2.33 & 13.38 & 0.962 & 17.4 \\
\hline D30 & 2.33 & 12.84 & 1.13 & 18.1 \\
\hline D40 & 2.33 & 12.27 & 1.31 & 19.0 \\
\hline D40* & 2.40 & 5.79 & 0.937 & 41.5 \\
\hline
\end{tabular}

Table 6: CEC RF-02-08 representative test fuel composition

\begin{tabular}{lrrr}
\hline & $\begin{array}{c}\text { DBE+1 } \\
(\% \mathrm{v} / \mathrm{v})\end{array}$ & \multicolumn{1}{c}{$\begin{array}{c}\text { DVPE } \\
(\mathrm{kPa})\end{array}$} & \multicolumn{1}{c}{$\begin{array}{c}\text { PN index } \\
(1 / \mathrm{kPa})\end{array}$} \\
\hline Fuel A & 2.20 & 61.7 & 3.56 \\
Fuel B & 2.49 & 59.9 & 4.16 \\
\hline
\end{tabular}

Table 7: Drive cycle test fuel composition

\begin{tabular}{crrr}
\hline & $\begin{array}{c}\text { DBE+1 } \\
(\% \mathrm{v} / \mathrm{v})\end{array}$ & \multicolumn{1}{c}{$\begin{array}{c}\text { VP* } \\
(\mathrm{kPa})\end{array}$} & $\begin{array}{c}\text { PN index } \\
(1 / \mathrm{kPa})\end{array}$ \\
\hline Fuel 1 & 2.11 & 106.1 & 1.99 \\
Fuel 2 & 1.98 & 92.9 & 2.15 \\
Fuel 3 & 2.32 & 56.2 & 4.07 \\
Fuel 4 & 2.28 & 47.8 & 4.77 \\
Fuel 5 & 2.95 & 57.3 & 5.14 \\
\hline \multicolumn{4}{l}{ rer DVPE or RVP depending on fuel analysis method }
\end{tabular}

Five fuels with a spread of the PN index were selected for the drive cycle experiments. At both ends of the PN index, fuels were selected that had a low (or 
high) index due to either a high (or low) Vapour Pressure or DBE, giving some form of independent control over these parameters. The properties of these fuels are shown in Table 7. Of note from these fuels, Fuel 3 is compliant with the EU5 reference fuel specification and Fuel 5 is a Japanese TRIAS certification fuel.

4

\section{RESULTS AND DISCUSSION}

\subsection{Spray image analysis and fFID results}

The previous observations about fuel dispersion [5] are supported by looking at images of the fuel spray during injection. Figure 2 shows parallel sets of false coloured image of the fuel spray, on the left, D40 (which includes $5 \% \mathrm{v} / \mathrm{v} \mathrm{n}$ pentane) and, on the right, D40* (D40 without n-pentane). It can be seen that the presence of n-pentane causes the fuel spray to break up more quickly, whereas the fuel without $n$-pentane disperses further into the cylinder before evaporation.

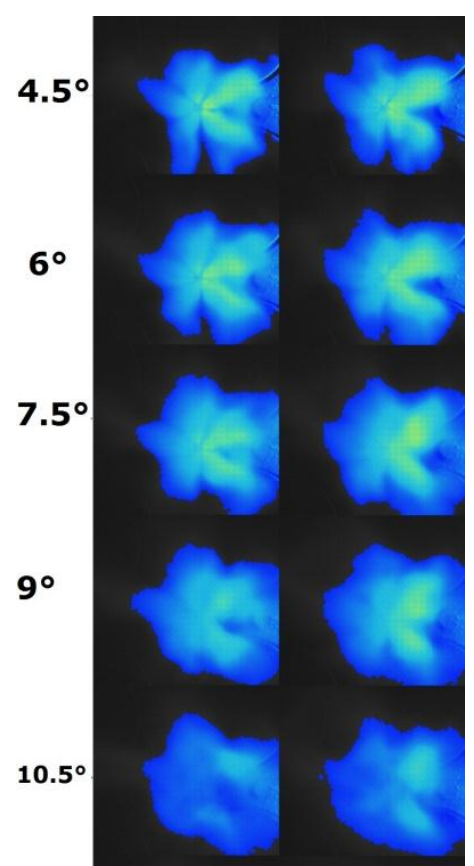

Figure 2: False colour images of the D40 fuel spray a) with pentane (D40) and b) without pentane (D40*), units of CAD after the start of injection

The evidence of the spray images is supported by fFID measurements. Figure 3 shows that the rise time of the D40* (no pentane) fuel is slower, and it has much lower cycle-to-cycle variation than the D40 (with pentane), again suggesting that the D40 fuel is forming a more homogeneous mixture than D40*. Recall that Figure 1 has already shown that the D40* fuel (no pentane) has a smaller circumferential variation. 


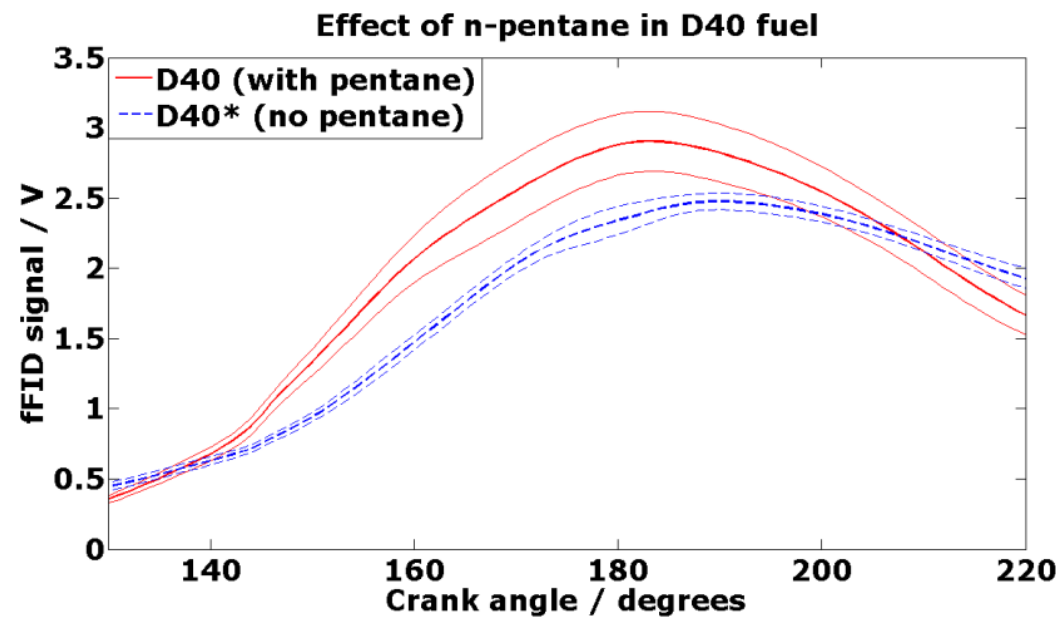

Figure 3: In-cylinder hydrocarbon levels sampled $10 \mathrm{~mm}$ below the cylinder head gasket and $45^{\circ}$ around from the front of the engine; the data bands correspond to $\pm \sigma$

\subsection{Model fuel results}

Results for model fuels tested in the single cylinder optical access engine are shown in Figure 4. It can be seen that the PN emission follows the trend of the index. Unfortunately the variation in PN index for fuels with fixed DBE and varying volatility is small, and as such the effects are difficult to discern amid the normal variations in particles emitted (the error bars here represent one standard deviation).

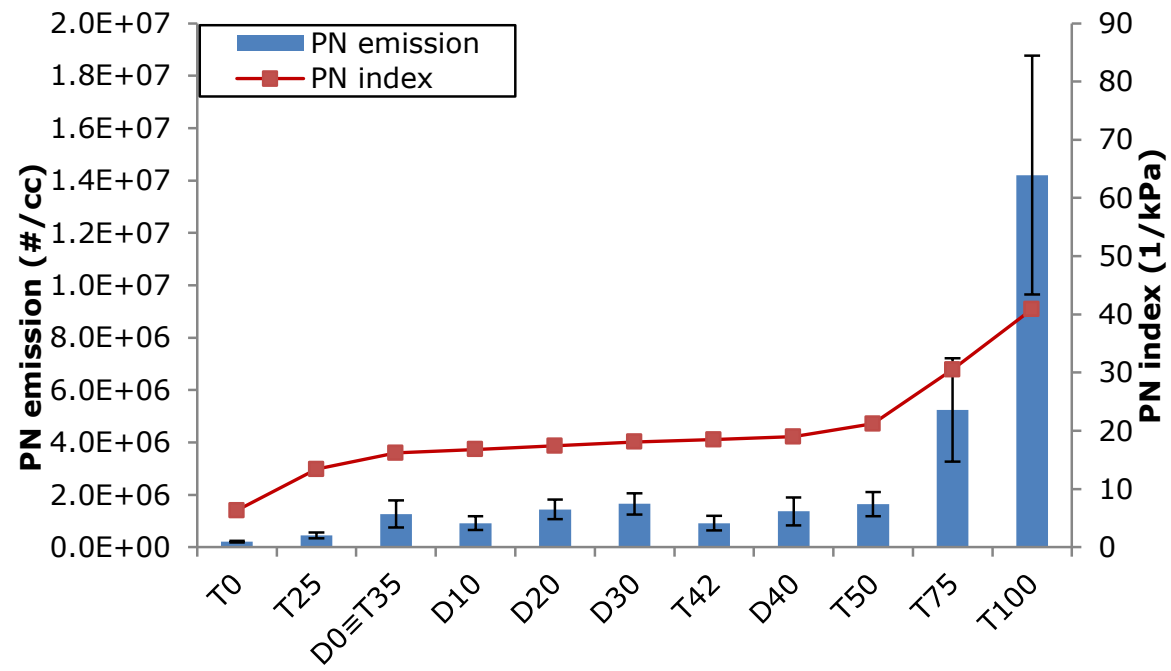

Figure 4: Accumulation mode Particulate Number emissions and PN index value variation for model fuels (independent control of DBE and VP)

The results shown in Figure 4 have been plotted again in Figure 5, this time comparing the PM index and PN index value of each of these fuels, the PN emission is shown as proportional to the area of the "bubbles" displayed (no error is plotted here for clarity, but the error can be seen on Figure 4). It can be clearly seen that 
the PN index appears to provide a better indication of the PN emission compared to the PM index, indeed two fuels with the same PN index, but very different PM indices (T42 and D40), give almost the same PN emission (within the error), and not the factor of 2 difference predicted by the PM index.

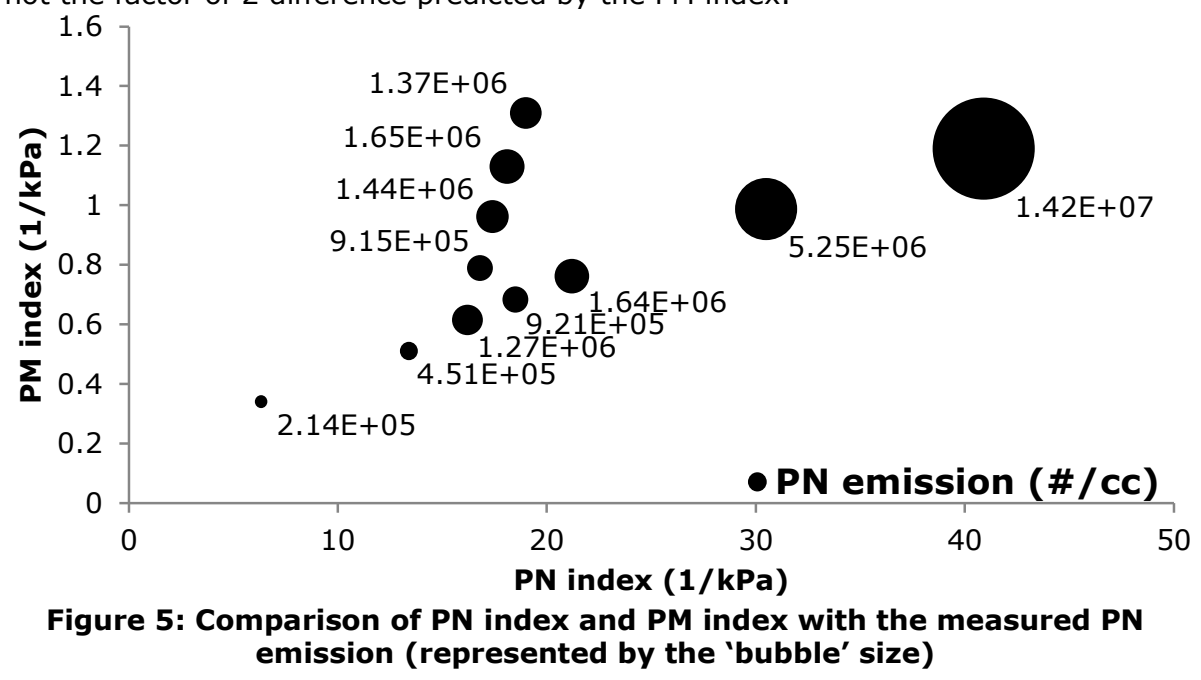

\subsection{Reference fuel results}

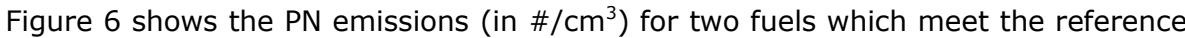
fuel specification for testing against EU5 emissions legislation. It can be seen that the trends of the index are followed both at a stoichiometric and a rich condition, with a difference in PN emissions of around $70-80 \%$ (in fact greater than the $24 \%$ predicted by the index). This has implications for the forthcoming EU6 emissions legislation, where PN emissions from gasoline vehicles will be regulated for the first time, as unless the reference fuel specification is changed or an allowance is made for a PN index, then batch to batch variations in PN emissions may be experienced with different fuels meeting the same specification.

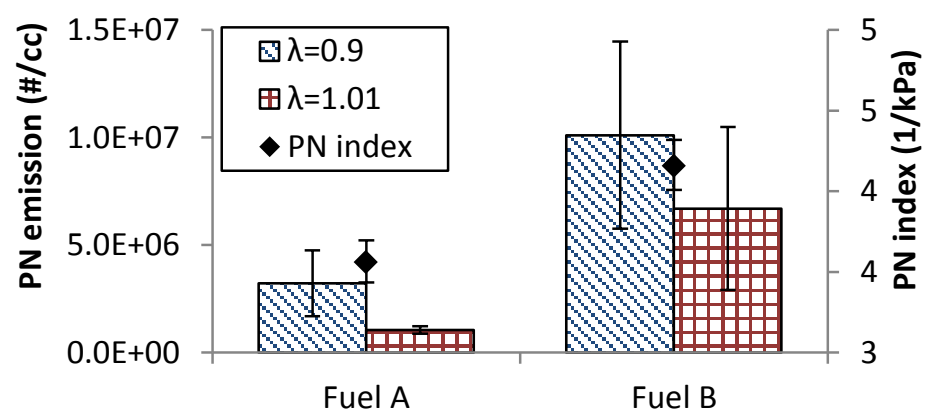

Figure 6: PN emissions from two fuels representing the EU5 Reference fuel specification

\subsection{Drive cycle results}

The results of the V6 drive cycle tests are shown in Figure 7. Each fuel was tested at least three times; with Fuel 3 being the first fuel tested (three times), and then repeated at the end a further three times. It can be seen that the repeat of Fuel 3 has given a highly repeatable result; reassuring that no drift effects have been present. It can be seen that there is some impact of the PN index, but much less than was predicted. This is reinforced in Figure 8, where the PN emission is plotted 
against the PN index, the correlation between the total emission and the index is relatively flat, although the PN index definitely still has an effect.

Breaking the cycle down into its constituent parts however reveals more detail. Here, the first $100 \mathrm{~s}$ of the cycle is referred to as the 'Cold Start', 100-800 s as the 'Urban', and 800-1180 s as 'Extra Urban'. Fuel 4 has the lowest VP of all the fuels, and so will take the longest to evaporate upon injection. This fuel also has the highest emission in the Extra Urban portion of the cycle, which requires the highest load from the engine, suggesting perhaps that some spray impingement is taking place - leading to higher PN emissions, while leaving emissions where full evaporation has taken place dependent more on DBE. Likewise the Urban portion of the cycle correlates better with the DBE of the fuel, Fuel 5 having the highest DBE, and the highest Urban emission. The Cold Start part of the cycle again seems to correlate best with VP, unsurprising perhaps given the dependence of this part of the cycle on fuel evaporation. The Cold Start, and use of stop-start, may also cause deviation from the results observed on the single cylinder, optical access engine, which was run fully warm.
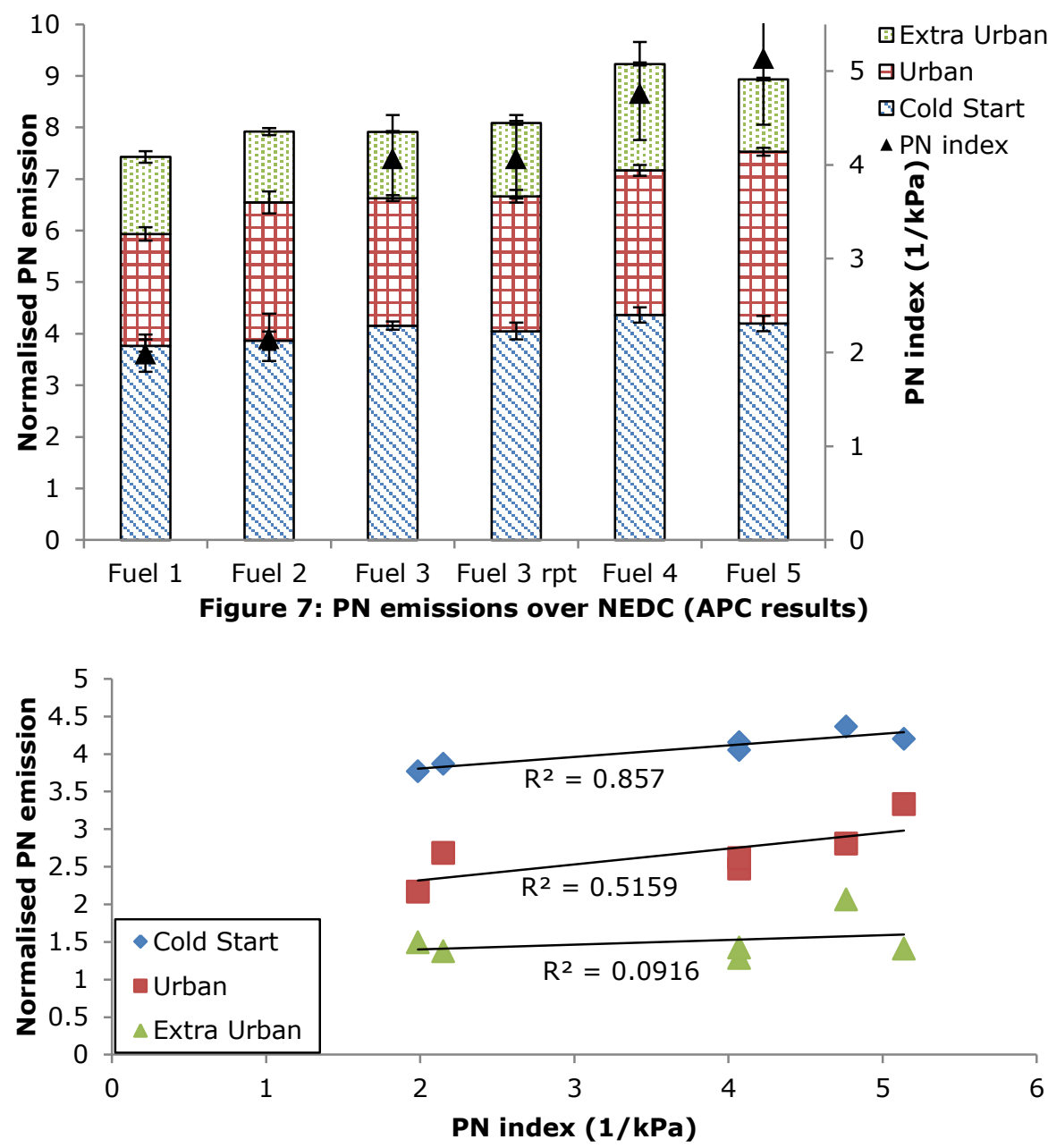

Figure 8: PN emission plotted against PN index (APC results) 
A range of fuels have been tested on two different Spray Guided Direct Injection gasoline engines. Use of high speed imaging has validated previously observed results of evaporation for model fuels being dependent on 'light-end' components being present in the fuel.

The PN results from a single cylinder, optical access engine validate previously observed results suggesting that the PN index is a useful tool in predicting PN emissions. It has been shown that two fuels meeting the EU5 reference fuel specification can have differing PN emissions at both stoichiometric and rich conditions, following trends predicted by the PN index. This has important implications for policy makers.

Drive cycle results have been more mixed, with other factors masking the effect of the PN index. In addition it has been seen that different parameters in the PN index have differing impacts on the PN emission from different parts of the NEDC.

\section{ACKNOWLEDGEMENTS}

This work was funded by the Engineering and Physical Sciences Research Council (EPSRC) and Jaguar Land Rover. The authors wish to thank David Richardson and Coryton Fuels for supplying the specially blended CEC RF-02-08 Reference Fuels. The authors also wish to thank Glyn Davies and Mike Braisher of Jaguar Land Rover for their assistance in undertaking the Drive Cycle experiments.

\section{REFERENCE LIST}

1. Zhao, H., Overview of Gasoline Direct Injection Engines, in Advanced direct injection combustion engine technologies and development: Gasoline and gas engines. 2010, Woodhead Publishing Ltd.

2. Braisher, M., C.R. Stone, and P. Price, Particle Number Emissions from a Range of European Vehicles. SAE Technical Paper, 2010. 2010-01-0786.

3. Commission Regulation 692/2008, OJ L 199 of 18.7.2008, p.130.

4. Aikawa, K., T. Sakurai, and J.J. Jetter, Development of a Predictive Model for Gasoline Vehicle Particulate Matter Emissions. SAE International Journal of Fuels and Lubricants, 2010. 3(2): p. 610-622.

5. Leach, F., D. Richardson, and R. Stone, The Influence of Fuel Properties on Particulate Number Emissions from a Direct Injection Spark Ignition Engine. SAE 2013 World Congress \& Exhibition. 2013-01-1558.

6. Commission Regulation 692/2008, OJ L 199 of 18.7 .2008$, p.88.

7. Sandford, M., G. Page, and P. Crawford, The All New AJV8, in SAE World Congress \& Exhibition, April 2009. 2009-01-1060.

8. Peckham, M.S., et al., Study of Particle Number Emissions from a Turbocharged Gasoline Direct Injection (GDI) Engine Including Data from a Fast-Response Particle Size Spectrometer, in SAE World Congress \& Exhibition, April 2011. 2011-01-1224.

9. Reavell, K., T. Hands, and N. Collings, A Fast Response Particulate Spectrometer for Combustion Aerosols, in SAE Powertrain \& Fluid Systems Conference \& Exhibition, October 2002. 2002, SAE: San Diego, CA, USA.

10. Giechaskiel, B., et al., Calibration and accuracy of a particle number measurement system. Measurement Science and Technology, 2010. 21(4): p. 045102.

11. Cheng, W.K., T. Summers, and N. Collings, The fast-response flame ionization detector. Progress in Energy and Combustion Science, 1998. 24(2): p. 89-124.

12. Chen, L., R. Stone, and D. Richardson, A study of mixture preparation and $P M$ emissions using a direct injection engine fuelled with stoichiometric gasoline/ethanol blends. Fuel, 2012. 96: p. 120-130. 